\title{
Reconstructive aortic valve surgery in the elderly: Another example of better being the enemy of good?
}

\author{
Alan M. Speir, MD
}

\author{
From the Department of Cardiac Surgery, Inova Heart and Vascular Institute, Inova Health System, Falls Church, \\ Va. \\ Disclosures: Dr Speir is on the Medtronic North American Cardiac Surgery Advisory Board. \\ Received for publication Nov 26, 2017; accepted for publication Dec 2, 2017; available ahead of print Jan 18 , \\ 2018. \\ Address for reprints: Alan M. Speir, MD, Department of Cardiac Surgery, Inova Heart and Vascular Institute, 3300 \\ Gallows Rd, Falls Church, VA 22042 (E-mail: aspeir1@ gmail.com). \\ J Thorac Cardiovasc Surg 2018;155:1421-2 \\ $0022-5223 / \$ 36.00$ \\ Copyright (c) 2017 by The American Association for Thoracic Surgery \\ https://doi.org/10.1016/j.jtcvs.2017.12.004
}

In this month's edition of the Journal, Urbanski and colleagues ${ }^{1}$ describe their modifications of operative techniques and long-term results after aortic valve and root repair in patients 75 years old and older. This is another review of their single-center results, which have served to elevate the consciousness of the cardiac surgical community regarding the merits of these operative approaches to aortic valve pathology. Although Urbanski and colleagues ${ }^{1}$ clearly stipulate the merits of expeditious, predictable, and reproducible standard valve and root replacement techniques, they still present their rationale that they "believe that elderly patients with suitable pathological and clinical conditions can also profit from the advantages of valvesparing albeit more complex aortic repair techniques as has been demonstrated for the young.,"2,3

Since the advent of transcatheter aortic valve replacement, there probably has been more focus on the subject of valvular intervention in elderly patients than on most other topics in our specialty. Clearly, this debate of open aortic valve replacement versus transcatheter aortic valve replacement eclipses the scrutiny given to another widely debated subject: surgical myocardial revascularization versus percutaneous catheter intervention for coronary artery occlusive disease. As a result of these analyses, the reality is that open aortic valve replacement has been performed in the elderly population with acceptable operative results for mortality and morbidity. ${ }^{4,5}$ Although the postoperative convalescence is clearly more arduous in this elderly cohort, the recognition of satisfactory operative results in the patients undergoing open surgery should be the filter that we use to interpret this article by Urbanski and colleagues.

In the discussion section of their article, Urbanski and colleagues $^{1}$ repeatedly mention the operative challenges of the repair techniques and state that "even centers with the most extensive experience in the reimplantation technique do not recommend this method in risky or elderly

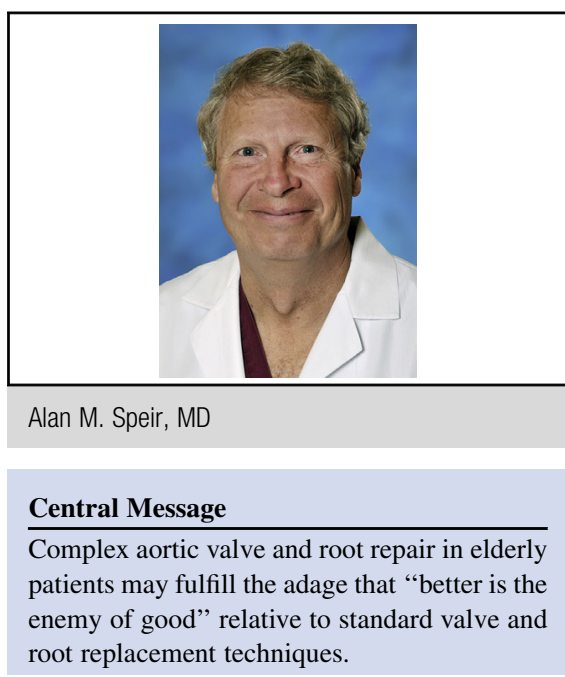

See Article page 1414 .

patients." ${ }^{6}$ Individual surgeon expertise is also mentioned as critical to the surgical outcomes. This point is further stressed that "the surgeons have to be quite sure about the primary surgical and functional results, because any corrections are connected with a second run and prolonged operative times (ischemia, cardiopulmonary bypass), which are not tolerated as well as by younger patients.",

The central issue, therefore, is not whether gifted and experienced surgeons can obtain excellence with these demanding procedures, but whether those surgeons with less experience in centers with lower populations of patients with these pathologies should consider these procedures, rather than the more commonly performed valve replacements with standard stented bioprostheses or composite grafts. The enemy of good may not, in fact, be better in many less-experienced hands attempting these techniques in the higher-risk cohort of elderly patients.

\section{References}

1. Urbanski PP, et al. Reconstructive aortic valve surgery in the elderly: techniques and outcomes. J Thorac Cardiovasc Surg. 2018;155:1414-20.

2. Fok M, Shaw M, Sancho E, Abello D, Bashir M. Aortic valve repair: a systematic review and meta-analysis of published literature. Aorta (Stamford). 2014;2: $10-21$.

3. Bashir M, Oo A, De Paulis R, Borger MA, El Khoury G, Bavaria J, et al. Can the results of aortic valve repair equal the results of a biologic aortic valve replacement? Aorta (Stamford). 2014;2:1-9.

4. Okamoto Y, Yamamoto K, Yoshii S. Early and late outcomes of aortic valve replacement using bioprosthetic versus mechanical valve in elderly patients: a propensity analysis. J Card Surg. 2016;31:195-202. 
5. Kato Y, Tsutsumi Y, Kawai T, Goto T, Takahashi Y, Ohashi H. Aortic valve replacement for aortic stenosis in the elderly: influence of prosthesis-patient mismatch on late survival and left ventricular mass regression. Gen Thorac Cardiovasc Surg. 2008;56:397-403.
6. Shrestha M, Baraki H, Maeding I, Fitzner S, Sarikouch S, Khaladj N, et al. Long-term results after aortic valve-sparing operation (David I). Eur J Cardiothorac Surg. 2012;41:56-61; discussion $61-2$. 